\title{
Deconstruyendo el MENA desde una perspectiva histórica y cultural. El concepto de 'Middle East and North Africa' como producto funcional occidental
}

\author{
Laura Sestafe Silvestre*
}

\begin{abstract}
RESUMEN
La categoría analítica de "Middle East and North Africa" hace referencia a un conjunto de países que comparten un bagaje histórico, social y cultural. Sin embargo, dependiendo de la institución o individuo que lo emplee, incluye o excluye una serie de países, lo que generalmente se justifica en términos culturales o geográficos. No obstante, su empleo en Occidente tiene una profunda relación con los estudios orientales desarrollados durante los siglos XVIII y XX, mantenida por su utilidad política. El orientalismo ha sido un rasgo característico del discurso político occidental desde la colonización hasta la Guerra Fría, cuando una parte importante de la academia trató de justificar el status quo del mundo mediante teorías políticas o culturalistas, no solo con la tradicional representación de las diferentes regiones mundiales, sino atribuyéndoles un papel en el orden mundial de la Guerra Fría directamente relacionado con su valor geoestratégico para Occidente. En el presente artículo, se expone la aportación de la producción intelectual y académica occidental en la construcción histórica de la categoría analítica del MENA, y su formulación dentro de una disciplina y discurso concreto.
\end{abstract}

Palabras clave

MENA; orientalismo; geopolítica; Guerra Fría; choque de civilizaciones.

\section{TitLe}

Deconstructing MENA from a historical and cultural perspective. The concept of "Middle East and North Africa" as a Western functional product

\begin{abstract}
The analytical category of "Middle East and North Africa" refers to a set of countries that share a historical, social and cultural background. However, it may include or exclude a number of countries depending on the institution or individual who applies this category, which is usually justified in cultural or geographical terms. Still, the use of this concept is deeply connected with Oriental studies, as they developed during the 18th and 20th centuries and Western geopolitical interests in the region. Orientalism has been a common feature of Western political discourse from colonization to the Cold War. In this last period, many scholars expected to justify the post-IIWW world order through political and culturalist theories, not only using the conventional orientalist approach to the different regions of the world, but assigning them a particular role in the new world order depending of Western interests. This paper intends to show the contribution of Western intellectual and scholar production in the historical construction of the analytical category of MENA, and its formulation within specific academic discipline and political discourse.
\end{abstract}

\section{KEYWORDS}

MENA; orientalism; geopolitics; Cold War; Clash of Civilizations.

DOI:

https://doi.org//0.15366/relacionesinternacionales2019.42.004
Formato de citación recomendado:

SESTAFE SILVESTRE, Laura. "Deconstruyendo el MENA desde una perspectiva histórica y cultural. El concepto de 'Middle East and North Africa' como producto funcional occidental”, en Relaciones Internacionales, $\mathrm{n}^{\circ}$ 42, 2019 , pp. 55-76.
*Laura SESTAFE SILVESTRE,

Graduada en

Relaciones

Internacionales por la Universidad Rey Juan Carlos en el año 2016 y en el Máster de Historia Contemporánea a través de la Universidad

Autónoma de Madrid en el año 20I8. Actualmente, se encuentra investigando con el objetivo de iniciar el Doctorado en Historia Contemporánea por la Universidad Autónoma de Madrid, centrándo su tesis el análisis del papel que tuvieron los Estados Unidos durante el periodo de la Guerra Fría en el proceso de minimización de los movimientos de izquierda en Marruecos, Argelia y Egipto durante el periodo señalado.

Recibido: 28/04/2019 Aceptado: 08/07/2019 


\section{$\mathrm{I}$}

\section{ntroducción}

Desde las últimas décadas del siglo XX, diversas teorías "post-ismos" han cuestionado, denunciado y replanteado el uso de múltiples categorías que se mantenían profundamente arraigadas en el vocabulario político, económico, periodístico y académico' de buena parte del globo, pero especialmente en aquellos lugares donde estos términos fueron definidos: Europa y Estados Unidos. En lo que se refiere al acrónimo "MENA", utilizado para hacer referencia a un ente geográfico compuesto por Oriente Medio y el norte de África, este debate conceptual tampoco resulta nuevo. Sin embargo, este no ha destacado por su intensidad y amplitud dentro de la vasta disciplina que se refiere a las regiones del norte de África y Oriente Medio, y en especial, en su trascendencia a otras disciplinas y ámbitos que favorezcan un debate trasversal tanto desde Occidente ${ }^{2}$ como por parte de los actores regionales que se incluyen en el mismo.

Por el contrario, su uso ha seguido siendo recurrente en los medios de comunicación, en los análisis geopolíticos, los estudios y prospectivas económicas y en diversas disciplinas de la academia. Un ejemplo claro de la persistencia en su utilización vino dado a raíz de las Primaveras Árabes, tanto en prensa como en trabajos destinados a la predicción de la seguridad regional e internacional o centrados en su significación histórica, política, social y económica. Sin embargo, el mismo ente geográfico al que el acrónimo MENA pretende referirse varía de forma importante dependiendo de la organización, institución, entidad o individuo que lo emplee, pretendiendo pese a ello conservar el mismo significado: la denominación a un ente geográfico cuyos países comparten una serie de rasgos culturales suficientes para ser comprendidos como región.

Atendiendo al marco temático en el que sea empleado, es posible identificar dos formas habituales en cuanto al contenido al que hace referencia el MENA. Por un lado, MENA en un sentido de análisis político y social, donde generalmente excluyen a Sudán, Somalia y Djibouti, puede excluir a Turquía y Mauritania e Israel, manteniendo a Irán; por otro lado, en los análisis económicos, geoestratégicos o de seguridad regional e internacional, muy relacionados con análisis de índole política, sí es común encontrar a Turquía, Irán, Sudán, Mauritania, Somalia, Djibouti y, en ocasiones, incluso a Eritrea. Esta situación permite, por un lado, observar la inconsistencia conceptual de la categoría de MENA, cuyo significado varía con respecto a la temática y organización que lo utilice ya sea esta parte de la región que designa o externa a ella. Al mismo tiempo, justifica su existencia en la homogeneización política, social y cultural de territorios muy diversos entre sí, lo que elimina las complejidades propias de diferentes regiones o países que incluye. Dicha situación ha conducido a generalizaciones cuya consecuencia más clara es la invisibilización de dinámicas

\footnotetext{
Entre las más relevantes, pueden destacarse la teoría postcolonial (SAID, Edward. Orientalism, Pantheon, Nueva York, I 978; CHAKRAVORTY SPIVAK, Gayatri. "Can the Subaltern Speak? Speculations on Widow-Sacrifice” en Wedge, vol. 7/8, I985, CHAKRAVORTY SPIVAK, Gayatri. Critique of Postcolonial Reason: Towards History of the Vanishing Present, Harvard University Press Cambridge, I999; BHABHA, Homi K. The location of culture, Routledge, 1994) y el postestructuralismo (entre algunos de los trabajos más destacados se encuentran FOUCAULT, Michel. Madness and Civilization:A History of Insanity in the Age of Reason, Travistock Publications, I967; FOUCAULT, Michel. The Order of Things: An Archaeology of the Human Science, Travistock Publications, 1970;LYOTARD, Jean-François: The posmodern condition:A report on knowledge, University of Minessota Press, 1979; DERRIDA, Jacques: Of Grammatology, The Johns Hopkins University Press, I974; DELEUZE, Guilles y GUATTARI, Félix: Anti-Oedipus: Capitalism and Schizophrenia, Viking Press, Nueva York, 1977; o incluso BUTLER, Judith: Gender Trouble: Feminism and the Subversion of Identity, Routledge, Nueva York, 1990) o la teoría constructivista de las Relaciones Internacionales que, sin contar con el prefijo "post", generó un intenso debate en el ámbito de las Relaciones Internacionales (RI) al ser considerada una teoría "postmoderna" por parte de visiones tradicionales de las RI, como el realismo o el neorealismo (ver WENDT, Alexander: Social Theory of International Politics, Cambridge University Press, 1999, pp. I - 6).

2 Generalmente, la categoría de “Occidente” hace referencia geográfica a Europa occidental y Norteamérica. En lo referente a la producción académica e intelectual respecto a Oriente Medio y el Norte de África, dicha categoría incluiría Rusia y los países del este de Europa dada la especial importancia de la escuela orientalista rusa. Esto permite observar cómo Occidente no se trata tampoco de una categoría definida geográficamente y con un significado estático, sino de fronteras borrosas e importantes variaciones de contenido.
} 
específicas, generando un conocimiento parcial, impreciso y en ocasiones erróneo con respecto a los países que lo integran ${ }^{3}$.

Esta situación plantea de forma inmediata cuatro interrogantes: ¿por qué tiene un carácter elástico y no se mantiene estático el número de países que se incluyen en el MENA, qué actores deciden sobre ello y cómo se identifican los actores regionales a los que incluye? ¿cuál es la relevancia o la trascendencia de que esta categoría analítica sea elástica? ¿qué rasgos culturales e históricos son aquellos que permiten incluir o excluir a determinados países a interpretación del sujeto que lo estudia? ¿cuán relevante es, en la construcción y definición del término MENA, que los países a los que se refiere perteneciesen a un imperio determinado en uno u otro momento de la historia, cuando existen diferentes experiencias históricas e identidades culturales y nacionales?

Dar respuesta a estos cuatro interrogantes constituye una tarea cuya ambición rebasa la capacidad de un solo artículo. Las dos primeras preguntas hacen referencia directa al carácter elástico del MENA como categoría analítica en términos de conceptualización, en tanto en qué actores definen esta categoría y cómo se perciben a sí mismos los actores regionales a los que hace referencia, lo que indirectamente implica observar qué dinámicas se derivan de esta cuestión entre los actores regionales que designa y otros actores internacionales. Estas cuestiones plantean un tema esencial en el debate en torno al MENA y han sido trabajadas desde la disciplina de las Relaciones Internacionales (RI) a lo largo de las últimas dos décadas por autores y autoras como Pinar Bilgin, Andrea Teti, Morten Valbjørn o Ramzi Rouighi ${ }^{4}$, cuyas aportaciones han supuesto la renovación de un debate que lleva planteándose desde la década de 19705. Aunque en los últimos años ha aumentado la atención sobre el debate anteriormente mencionado ${ }^{6}$, la reflexión crítica respecto al término de MENA no ha constituido una línea de investigación prioritaria en las RI ni en otras disciplinas fundamentales para la comprensión de su origen, evolución, connotaciones y deconstrucción, como en este caso lo es la Historia.

El artículo no se centra en la adopción y utilización del concepto de MENA en los territorios a los que generalmente hace referencia. Tampoco pretende negar que los territorios árabes del norte de África y Oriente Medio se hayan definido en determinados periodos históricos como una entidad geográfica específica atendiendo a cuestiones culturales e históricas, incluso con aspiraciones a constituirse como una única entidad política, dado que estas son precisamente las características del panarabismo como corriente ideológica en la segunda mitad del siglo XX.

\footnotetext{
3 Un ejemplo claro de esto puede encontrarse, de nuevo, con las Primaveras Árabes. Tanto en la lectura que se hizo desde las instituciones de la Unión Europea y los Estados Unidos, como en la producción bibliográfica donde se evaluaban las protestas de forma monolítica, tanto de forma general como en bloques de países, eludiendo un análisis previo y exhaustivo de las circunstancias sociopolíticas y económicas de las que partía cada estado y las demandas particulares realizadas por los diferentes actores partícipes en las movilizaciones sociales en cada país. TETI, Andrea y ABBOTT, Pamela. "What People Want? The Demand for Democracy in Six Middle Eastern States" en Report number: Arab Transformations Policy Brief I, Universidad de Aberdeen, enero de 2018;TETI, Andrea. "Bridging the Gap: IR, Middle East Studies and the Disciplinary Politics of the Area Studies Controversy” en European Journal of International Relations, vol. I3, n I, pp. II9 - I 20.

4 BILGIN, Pinar.“Whose 'Middle East?' Geopolitical Inventions and Practices of Security” en International Relations, vol. I8, n I, pp. I7 - 33;TETI, Andrea. "Bridging the Gap...”, op. cit. Pp. I 77 - I45;VALBJØRN, Morten. "The Meeting of the Twain: Bridging the Gap between International Relations and Middle East Studies" en Cooperation and Conflict, vol 38, n², pp. 163 - 173, 2003; ROUGHI, Ramzi. "Why are there no Middle Easterners in the Maghrib" en BONINE, Michael. E,AMANAT,Abbas, GASPER, Michael Ezekiel (eds.) en Is There a Middle East? The evolution of a geopolitical concept, Stanford University Press, Stanford, 2012, pp. 100 - 116.

5 KEDDIE, Kikki. “Is There a Middle East?" en International Journal of Middle East Studies, vol. 4, n 3, 1973, pp. 255-27I; BONINE, E. Michael. "Where is the geography of the Middle East", en The Professional Geographer, vol. 28, n 2, 1976.

6 Este debate se ha nutrido además de aportaciones con enfoques interdisciplinares muy interesantes, como es destacable en el caso de TETI, Andrea. "Bridging the Gap...", op. cit;VALBJØRN, Morten. "The Meeting of the Twain ...op. cit.
} 
Asimismo, sería incurrir en un error considerar que los actores regionales a los que designa permanecieron impermeables al concepto. Si bien la creación de la categoría analítica de MENA, en los términos en los que se utiliza en diversos ámbitos de forma global, tiene en su construcción histórica un componente muy relevante de designación y representación por parte de Occidente, eso no implica que no haya generado dinámicas propias de autopercepción e identidad dentro de este espacio geográfico. El arabismo como corriente ideológica surgida en la primera mitad del siglo XX y el panarabismo durante la segunda mitad de este siglo son una buena muestra de ello ${ }^{7}$.

Desde esta perspectiva, se hace evidente la importancia de incidir en el estudio de las dinámicas histórico-culturales que desde Occidente contribuyeron en la creación de la categoría analítica del MENA, ya que dicha cuestión influye directamente en la manera de comprender, estudiar y analizar diversas cuestiones relativas a los países que incluye. Por ello, el presente artículo se centra en responder a las dos últimas preguntas de investigación formuladas, relativas a las circunstancias históricas y culturales de la región, su tratamiento a través de la producción intelectual y académica occidental ente los siglos XIX y XX y la importancia actual de ello en la definición de la categoría analítica del MENA y su popularizado empleo en diversos ámbitos, con el objetivo de contribuir al debate existente en cuanto a su utilización en el estudio de los países del norte de África y Oriente Medio en el ámbito de la Historia y las Relaciones Internacionales ${ }^{8}$. Así, lo que motiva este artículo es en señalar, destacar y exponer el proceso de construcción de la categoría de MENA en la producción académica e intelectual occidental, su trascendencia al ámbito político, la persistencia de estas cuestiones entre algunos sectores políticos, académicos y la popularización de una representación eurocéntrica de la región mediante los medios de comunicación. En definitiva, en cómo este proceso de producción intelectual y académica en Occidente ha afectado a la visión y comprensión tradicional, e incluso actual, de los territorios comprendidos por la categoría analítica del MENA en los países occidentales.

Para ello, el artículo se estructura en dos apartados: uno primero donde se analiza a través de un breve recorrido histórico los elementos históricos y culturales que han sido considerados como vínculo esencial y suficiente para la comprehensión de los países del norte de África y Oriente Medio, y un segundo apartado en el cual se realiza un análisis crítico de las dinámicas políticas y culturales de la producción académica orientalista respecto al norte de África y Oriente Medio, donde se pone de manifiesto la representación homogénea del conjunto de países de mayoría musulmana situados en el norte de África y en Oriente Medio, y que ayudaron a consolidarlo como categoría analítica. De esta forma, en el artículo se utiliza la extensión geográfica máxima que el concepto de MENA puede llegar a designar?: al referirnos al norte de África nos centramos

7 BILGIN, Pinar. “Whose 'Middle East?'...”, op. cit.

8 En este sentido, la cuestión que más interesa como objeto de estudio es la visión homogénea que se proyecta de los países de los que se compone dicha categoría, y no en si ha terminado siendo validado mediante su utilización por determinados actores regionales en organizaciones internacionales o en estudios académicos, dado que también es posible encontrar actores regionales que niegan su validez.

9 Los países que integran la región MENA en su máxima extensión geográfica serían Argelia, Bahrein, Egipto, Djibouti, Iraq, Israel, Irán, Jordania, Kuwait, Líbano, Libia, Mauritania, Marruecos, los Territorios Ocupados de Palestina,Turquía, Omán, Qatar,Arabia Saudí, Siria,Túnez, los Emiratos Árabes Unidos y Yemen. Estos países se han seleccionado teniendo en cuenta la lista de países recogidos en la web del Alto Comisionado Derechos Humanos de las Naciones Unidas (https://www.ohchr.org/en/countries/menaregion/Pages/MenaRegionlndex.aspx [consultado el I5/03/2019]; en la web del Banco Mundial (https://www.worldbank.org/en/region/mena [consultado el I5/03/2019]; la Estrategia de Política Exterior y de Seguridad de la Unión Europea (2016) (http://eeas.europa.eu/archives/docs/top_stories/pdf/eugs_review_web.pdf [consultado el I5/03/20I9)]; y el Informe Final (2019) del Proyecto MENARA, gestionado por el CIDOB (https://www.cidob.org/es/publicaciones/ serie_de_publicacion/menara_papers/working_papers/the_mirage_of_regionalism_in_the_middle_east_and_north_africa_post_20I I [consultado el I5/03/2019]. 
en Mauritania, Marruecos,Argelia,Túnez, Libia, Sudán del Norte (en adelante Sudán) y Egipto, en el Oriente Medio a los países del Golfo Pérsico, Líbano, Siria, Israel, Jordania, Iraq e Irán, y el cuerno de África engloba a Dibouti y Somalia.

Para conseguir sus objetivos se centra esencialmente en realizar una evaluación de los elementos históricos y culturales por los que se ha vinculado las regiones del norte de África y Oriente Medio, así como en la revisión historiográfica que permite observar dicho proceso de homogeneización. Para ello, en la elaboración del primer apartado se ha utilizado una abundante y diversa bibliografía procedente de fuentes secundarias, mientras que en el segundo apartado se emplean de forma extensa fuentes primarias que corresponden a artículos de prensa y bibliografía historiográfica que han constituido un punto de referencia esencial en los estudios orientalistas específicos de Oriente Medio y el norte de África.

Por tanto, aun partiendo de la ampliamente consolidada base teórica respecto al carácter construido de la categoría analítica de MENA, es de nuevo importante incidir en que dicha construcción no ha sido un proceso unilateral ni al margen de los actores regionales que designa, sino que han tanto existido dinámicas de retroalimentación e hibridación conceptual y generadoras de identidad. La variación de las percepciones de la región a lo largo de la historia y su definición geográfica, tanto por parte de Occidente como por parte de los actores regionales que designa, se ha producido tanto por motivos políticos, económicos y tecnológicos como culturales o ideológicos ${ }^{10}$.

Así, los objetivos fundamentales del presente artículo es la exposición y análisis de la aportación de la producción intelectual y académica occidental a la construcción de la categoría analítica de MENA, su dimensión y empleo político en Occidente, su popularización mediática a nivel global y algunas claves respecto a las consecuencias que pueden observarse de dichos procesos. Por ello, el artículo se nutre del marco teórico propio de la teoría postcolonial que, a su vez, participa de la teoría constructivista en el ámbito de las Relaciones Internacionales, dado que la deconstrucción del MENA mediante el análisis de su construcción influye no solo en su empleo genérico como categoría analítica, sino en su consideración como actor internacional.

\section{Deconstrucción histórica y cultural del MENA. Sincretismos, idiosincrasia y plura- lidad cultural y étnica en el norte de África y Oriente Medio.}

Este artículo parte de la tesis de que, en la construcción de la categoría analítica de MENA tal y como se emplea de forma generalizada en la actualidad, ha existido un componente importante de representación por parte de Occidente de los territorios del norte de África y Oriente Medio. En este proceso, la producción intelectual orientalista tiene un papel central respecto a la homogeneización cultural de las sociedades que se incluyen en estos territorios, asimilado posteriormente para designar un punto de gran importancia geoestratégica para Europa y Estados Unidos.

Siendo el islam como religión mayoritaria el rasgo que comparten todos los países mencionados y la justificación por la cual se incluye a Turquía o Somalia, sería incurrir en un error limitarse a considerar que es el único elemento por el cual se aúnan a estos países en una sola región. Esta homogeneización no se produjo de forma exclusiva por el islam, sino por la

\footnotetext{
10 BILGIN, Pinar."Whose 'Middle East?'...”, op. cit. pp. 19 - 20.
} 
consideración de que los países incluidos en el MENA son parte de una misma cultura debido a una experiencia histórica común. Para realizar la deconstrucción del MENA como categoría analítica, es necesario hacer una breve referencia a la relación entre "lo árabe" y el islam y a cómo esto ha influido en la imagen que se ha configurado del norte de África y Oriente Medio desde Europa y EEUU.

En su momento de máxima expansión durante el periodo omeya en los siglos VII y VIII, el califato árabe llegó a ocupar desde el sur de España, toda la costa y parte del interior del norte de África, la península arábiga, Mesopotamia, Persia y hasta el sur del Cáucaso, las regiones de Transoxiana e incluso la región del Indo, introduciendo así el islam en estos territorios". En este periodo, se llevaron a cabo diversas políticas destinadas a la arabización de los territorios conquistados para consolidar el poder del califato, teniendo este proceso una clara dimensión religiosa, como el establecimiento del árabe como lengua oficial del califato, la reforma monetaria o la arabización del arte islámico. Según Albert Hourani, entre el siglo VIII y el siglo X, la población musulmana en los territorios del califato pasaría de menos del 10\% a constituir la mayor parte de la población, una expansión que iba acompañada del árabe como lengua común a las sociedades desde Marruecos hasta la frontera persa, siendo además "el principal medio de expresión de la cultura literaria"'2.

Todo ello tendrá una profunda influencia en cuanto a la exportación de elementos culturales árabes que permanecerán en el norte de África y Oriente Medio incluso tras la progresiva desintegración del califato durante el periodo abasí, lo que puede verse en los imperios musulmanes almorávide y almohade en el sur de la península ibérica y todo norte de África entre los siglos $\mathrm{X}$ y XIII.Ambos imperios eran de origen bereber, grupo étnico que cuenta con su propia lengua, pero tras el proceso de arabización omeya mantuvieron el árabe como idioma y el islam como religión de sus imperios ${ }^{13}$. Esta confluencia entre el islam y la cultura árabe, y concretamente al árabe como lengua fundamental, también se expandirá por el continente africano con las rutas y vínculos comerciales entre los imperios del norte de África con diferentes pueblos del Sahel, lo que incluye el norte de los actuales países de Mauritania, Mali, Níger, Chad y Sudán; esto mismo se dio con los intercambios comerciales de los pueblos árabes de la península arábiga con aquellos del cuerno de África, lo que incluye los actuales países de Somalia, Eritrea y Djibouti ${ }^{14}$. El grueso demográfico de estos países no fue ni es en la actualidad árabe, sino que se compone por diversos grupos étnicos que poseían sus propias lenguas y prácticas religiosas.

La entrada del islam en el Sahel y cuerno de África no supuso la conversión y adaptación mayoritaria del islam por parte de las comunidades que residían en la región, sino un proceso progresivo que se realizaría sin que estas sociedades abandonasen sus prácticas religiosas

\footnotetext{
" BALCI, Bayram. Islam in Central Asia and the Caucasus Since the Fall of the Soviet Union. Oxford University Press, Nueva York, 20I8, pp. II - 20. KÜNG, Hans. El islam. Editorial Trotta, Madrid, 2006, pp. 25I - 252.

12 HOURANI,Albert. A History of Arab Peoples. Faber and Faber, I99I, pp. 46 - 49

${ }^{13}$ FIERRO, Maribel (Ed). The New Cambridge History of Islam, vol. II:The Western IslamicWorld Eleventh to Eighteenth Centuries. Cambridge University Press, Cambridge, 20I0, pp. 21 - 99; ROUIGHI, Ramzi. "The Berbers of the Arabs" en Studia Islamica, vol. I06, n I, 20I I, pp. 49-76.

${ }_{14}$ REBSTOCK, Ulrich. "West Africa and its early empires", en FIERRO, Maribel (Ed). The New Cambridge History of Islam, vol. II ...op. cit. pp. I 44 156; MAZURI, Ali A. "Religion and Political Culture in Africa" en Journal of the American Academy of Religion, vol. 53, $\mathrm{n}^{\circ}$. 4. 1985, pp. 8I7-8I9 (pp. 817-839); MARTIN, B.G. "Arab Migrations to East Africa in Medieval Times", en The International Journal of African Historical Studies, vol. 7, $\mathrm{n}^{\circ} .3$, 1974, pp. $369-370$ (pp. 367-390).
} 
tradicionales, produciéndose nuevos sincretismos culturales ${ }^{15}$, en lo que algunos autores definen como la africanización del islam ${ }^{16} \circ$ el islam africano ${ }^{17}$. Dentro de las élites políticas y de las comunidades africanas tendrían lugar diferentes dinámicas de islamización y sincretismos entre la cultura árabe y las culturas propias del Sahel y el cuerno de África. Ejemplo de ello pueden ser el uso del árabe o la corriente y rama seguidas dentro del islam: mientras que en países como las actuales Somalia, Malí o El Chad, aunque el árabe se convertiría en idioma oficial, las comunidades continuaron utilizando mayoritariamente las lenguas locales, en Sudán y en Mauritania el árabe se convertiría en la lengua popular ${ }^{18}$. Por otro lado, siendo la población musulmana del Sahel y el este de África mayoritariamente suní, en Sudán, Eritrea y Etiopía las ordenes sufíes tienen una gran importancia y son muchos los seguidores de esta corriente ${ }^{19}$, sin que sin embargo estos dos últimos países se incluyan dentro de la región del MENA.

De esta forma, la expansión de las comunidades árabes procedentes de la península arábiga se limitará geográficamente a las regiones de Oriente Medio y el norte de África, mientras que la expansión del islam trascenderá estas fronteras. Aunque el grado de arabización del islam a partir del siglo XIII será muy inferior a periodos anteriores, se mantuvieron ciertos elementos de la cultura árabe impregnados. Entre ellos, el árabe como lengua para los actos religiosos y su estudio, la influencia árabe en el arte islámico y una de las cuestiones más importantes: la situación geográfica de los dos lugares más santos del islam, la Meca y Medina, situadas en la península arábiga y custodiados históricamente por comunidades de origen árabe ${ }^{20}$.

A pesar de estos elementos culturales árabes indivisibles de la fe islámica, las dos potencias regionales que se impondrían en el s. XVI, el Imperio Otomano y el Imperio Safávida, siendo el primero suní y el segundo chií, preservarían su cultura de origen frente a la árabe, esto es, la turca y la persa respectivamente. La extensión del Imperio Safávida abarcaba todo el Irán actual y la parte este de Iraq, donde habían existido imperios anteriores en los cuales el persa había sido el idioma oficial y en el que existía una gran producción literaria. Por otro lado, el Imperio Otomano se extendía desde los Balcanes y la Anatolia al límite con el Imperio Safávida, la región del Hiyjaz (donde se encuentran la Meca y Media), el norte de África hasta la actual Argelia y todas las provincias árabes de Oriente Medio.

Por su parte, los sultanes del Imperio Otomano mantuvieron el título de califas desde el s. XVI hasta 1918, con el fin de la Primera Guerra Mundial. La derrota otomana frente a los Aliados en la Primera Guerra Mundial propiciará el reparto entre Francia y Gran Bretaña de las últimas

\footnotetext{
15 Existen diferentes posiciones entre los especialistas sobre el islam en África con respecto a si se crearon sincretismos culturales entre la cultura árabe, el islam y la cultura local, o si la implementación del islam en las sociedades del Sahel y África del este dio lugar a una concepción "nueva" y propia del islam, siendo esto lo que se puede denominar Islam Africano.

16 MAZURI, Ali A. "Religion and Political Culture...." op. cit. pp. 822 - 824; ROBINSON, David. Muslim Societies in African History. Cambridge University Press, 2004, pp. 42 - 58.

17 ROBINSON, David. Muslim Societies in African... op. cit.; INSOLL, Timothy. The Archaeology of Islam in Sub-Saharian Africa. Cambridge University Press, Cambridge, 2003.

18 'ABD AL-RAHIM, Muddathir. "Arabism, Africanism, and Self-Identification in the Sudan" en The Journal of Modern African Studies, vol. 8, $\mathrm{n}^{\circ}$. 2 , PP.233-249; SHARKEY, HEATHER J. “Arab Identity and Ideology in Sudan:The Politics of Language, Ethnicity, and Race”, en African Affairs, vol. I07, n²26, 2008, Pp.2I-43

19 MAZURI, Ali A. "Religion and Political Culture...." op. cit. pp. 836;VIKOR, S. Knut. "Sufi Brotherhoods in Africa" en LEVTZION, Nehemia y POWELS, Randall. L. The History of Islam in Africa. Ohio University Press, Atenas, 2000, pp. 450.

20 HAYKEL, Bernard. "Western Arabia and Yemen during the Ottoman period" en FIERRO, Maribel (ed.) The New Cambridge History of Islam, vol. II:The Western...op. cit. p. 445.
} 
provincias árabes que, aunque en algunos casos nominalmente, había mantenido hasta entonces el Imperio Otomano: las actuales Siria, Líbano, Jordania y la parte este y central de Iraq. Sin embargo, desde mediados del siglo XIX, tanto Francia como Reino Unido habían comenzado sus primeras incursiones en el norte de África y la costa mediterránea de Oriente Medio.A principios del siglo XX, Francia había establecido protectorados desde Marruecos hasta Túnez, Italia en Libia y Reino Unido en Egipto, Yemen del Sur y los emiratos de Qatar y Kuwait, además de adentrarse en los territorios musulmanes del Sahel y África del este ${ }^{21}$.A pesar de sus intentos, Irán nunca llegó a ser un protectorado británico y se mantuvo como estado independiente ${ }^{22}$, siendo junto Arabia Saudí -estado guardián de la Meca y Medina desde 1925- y Yemen del Norte los únicos territorios que no acabarían perteneciendo en algún momento del siglo $\mathrm{XIX}$ y $\mathrm{XX}$ a una u otra potencia europea.

Desde finales del siglo XIX y principios del siglo XX, durante la presencia del Imperio Otomano en las provincias árabes de Oriente Medio y la colonización europea del norte de África, comenzó a propagarse entre una clase media educada y la élite intelectual árabe la idea de la existencia de una identidad propia árabe que diferenciaba a esta comunidad frente a los occidentales, los otomanos, los persas, la población racializada del Sahel y frente a otras minorías étnicas, como los kurdos o los bereberes. Como indica Youssef M. Choueiri, durante las primeras tres décadas del siglo XIX surgieron diversos movimientos nacionalistas y doctrinas ideológicas nuevas con respecto a modelos anteriores. Esto tuvo una fuerte influencia en el deseo de desarrollar una base teórica que sustentase la independencia de los pueblos árabes frente a los opresores otomanos y europeos ${ }^{23}$, que se vio reforzado y justificado a raíz de la Declaración de Balfour. En sus inicios, el arabismo como identidad se basaba en unos valores culturales y una historia compartida: una narración histórica, filosófica y espiritual que ponía mucho énfasis al periodo de grandeza durante la expansión del califato omeya, y que se consideraba justificada a través del legado histórico árabe a través de la literatura, el arte y la arquitectura ${ }^{24}$.

El arabismo como identidad supuso el cimiento del desarrollo teórico del panarabismo, siendo su base ideológica la unión y solidaridad entre todos los pueblos árabes. Desde sus inicios, el panarabismo incluyo al islam como rasgo diferenciador de los árabes por sus diversas implicaciones: ser la etnia del Profeta, el idioma en el que está escrito el Corán y en el que debe estudiarse el derecho islámico y por su importancia cultural histórica. A pesar del peso del islam dentro de la idea virtual de comunidad árabe, las líneas teóricas de sus ideólogos más relevantes enfatizan el papel de la religión como agente ético y moral, defendiendo la secularidad en la construcción de estados modernos, como puede verse en las ideas de Qustantine Zurayq, Sati al-Husri, Zaki al-Arsuzi, Shaikh Abdallah al-Alayili Abdallah o Michael Aflaq ${ }^{25}$.

Entre 1860 y 1870 , aproximadamente tres décadas antes del surgimiento del panarabismo

\footnotetext{
${ }^{21}$ KNUT.Vikor. "Sudan, Somalia and the Maghreb to the end of the First World War" en The Cambridge History of Islam, vol.V:The Islamic World in the Age of Western Dominance, pp. I24-133.

${ }^{22}$ Para una lectura ampliada de esta temática, se recomienda Modern Iran: Roots and Results of Revolution, de Nikki Keddie.

${ }^{23}$ CHOUEIRI, Youssef. M. Arab Nationalism. A history. Blackwell Publishers, Oxford. 2000, p. 125. Algunos miembros de la clase media y élite intelectual árabe abogaban por la descentralización, más que con la independencia, especialmente con el estallido de la Primera Guerra Mundial. ATÇIL, Abdurrahman, "Decentralization, Imperialism, and Ottoman Sovereignty in the Arab Lands before 19|4: Shakīb Arslān's Polemic against the Decentralization Party", en Die Welt des Islams, vol. 53, nI, 20I3, pp. 26 - 49.

${ }^{24}$ CHOUEIRI,Youssef. M. Arab Nationalism...op. cit. pP 126 - 128.

25 Ibidem, pp. $128-165$.
} 
como movimiento ideológico, encontramos el surgimiento del panislamismo. Dicho movimiento no surge como ideología propia y unificada, sino que constituye una de las ideas fundamentales sobre las que se asienta la salafiyya ${ }^{26}$, cuyo origen y teorización se atribuye a Jamal al-Din alAfghani, Muhammad Abduh y Rashid Rida. La salafiyya pretendía el resurgimiento y revitalización del islam mediante el regreso a los principios fundamentales del islam, a su experiencia tal y como lo vivieron los primeros musulmanes, eliminando toda influencia cultural occidental pero incluyendo los avances científicos y tecnológicos que pudiesen ser beneficiosos para la umma De hecho, al-Afghani y Abduh fundarían la escuela de pensamiento islámico modernista, tratando de compaginar la ortodoxia islámica, la moderación política y los avances científicos y técnicos occidentales ${ }^{27}$.

Partiendo de esa base, el panislamismo se desarrollaría como movimiento que buscaba la unidad de la comunidad musulmana y su adscripción a una lectura ortodoxa del Corán y la sharía, siendo esta la única forma de preservar la integridad islámica y recuperar el esplendor de la que había gozado la umma durante el inicio del califato. No surgió como reacción a la secularidad panarabista, y ciertamente tampoco ocurrió a la inversa, sino que fueron diferentes reacciones a una misma problemática. Ambos compartían una base antimperialista, anticolonial e incluso nacionalista, en tanto que ambos nacieron como movimientos que, apelando a una identidad cultural específica y su unidad, se irguieron contra la opresión colonial en demanda de la independencia de los territorios colonizados. Sin embargo, tanto la comunidad a la que se refieren como el modelo estatal e ideológico que plantean tras la independencia difieren considerablemente: mientras el panarabismo se refiere al conjunto de pueblos árabes, el panislamismo apela a la comunidad de creyentes musulmanes, y mientras que el primero generalmente busca la construcción de estados árabes modernos, seculares y solidarios entre sí, el panislamismo situaba el islam como vertebrador político, económico y social de los estados, defendiendo la imposibilidad de separar la política y la religión en el islam dado que este regula todos los ámbitos de la vida de la umma, por lo que el fin último debe ser el establecimiento de un estado islámico dirigido por la sharía.

De esta forma, el islam tiene una relación directa con la cultura árabe en tanto que surgió en la península arábiga, donde se encuentran los dos lugares más santos del islam, el Profeta Muhammad era de origen árabe y el Corán, los hadith y la sharía están escritos en árabe, idioma en el que históricamente se ha estudiado también el derecho islámico. En el caso de los pueblos del Sahel y del cuerno de África, estos africanizarían el islam y se desvincularían en gran medida de la influencia árabe en el mismo, como también ocurriría en los territorios del Imperio Otomano fuera de las provincias árabes, en el Imperio Safávida y sucesores persas.

\section{Evolución y consolidación de la imagen del norte de África y Oriente Medio en Eu- ropa y Norteamérica: la utilización política de los estudios orientalistas.}

El punto anterior pretendía exponer cómo, aun siendo árabes la gran mayoría de los países que se incluyen dentro del MENA, coexisten en la región diferentes pueblos cuyas culturas son igualmente longevas y se han preservado tras su conversión al islam, revirtiendo la arabización

\footnotetext{
${ }^{26}$ Esta doctrina islámica se inscribe en la escuela jurídica hanbalí, una de las cuatro escuelas jurídicas del islam suní. Algunos autores defienden que la salafiyya, en tanto que doctrina ideológica y espiritual definida, no aparece como tal en los textos de al-Afghani ni en los de Abduh, sino a partir de Rashid Rida.

27 LAUZIÈRE, Henri. "The Construction of Salafiyya: Reconsidering Salafism From The Perspective Of Conceptual History”, en International Journal of Middle East Studies, vol. 42, n 3, agosto del 2010. p. 375.
} 
del islam a pesar de los rasgos culturales árabes de los que no es posible desvincular esta religión. Desde el siglo XIX, las personas dedicadas al estudio de las sociedades del norte de África y Oriente Medio se denominaba orientalistas, fuese cual fuese la materia de estudio. El motivo era evidente: estudiaban "el Oriente”, que se extendía desde los países árabes del norte de África que no se circunscribían a los estudios africanos- hasta abarcar todo Asia.

Esta amplísima y ambigua masa geográfica fue el punto inicial de la tesis de Edward Said en Orientalismo, publicada en 1978, sobre la construcción de Oriente como un compartimento definido, imaginado y representado por Occidente. La división en compartimentos del mundo desde el siglo XVIII hasta pasada la segunda mitad del siglo $\mathrm{XX}$, implicaba, en cierta forma, que Oriente comprendía todo aquello que no fuese Occidente, un "Otro" frente a un "Nosotros" ${ }^{28}$. La capacidad de dominación e imposición occidental sobre las sociedades orientales se justificaba en la superioridad de los primeros como civilización, lo que generaba, por un lado, una labor moral de mission civilisatrice ${ }^{29}$ de África y Asia, donde el papel de la religión cristiana jugará un papel esencial, y por otro lado, legitimaba su capacidad de representar a las sociedades orientales, incapaces de hacerlo por sí mismas. El orientalismo no se limitaba a una disciplina académica aislada de las circunstancias políticas y económicas de las potencias primero coloniales y luego imperialistas ${ }^{30}$, ni en sus inicios en el siglo XVIII ni tras su reestructuración como disciplina académica en el siglo $X X$. Si bien el Oriente suscitaba un gran interés de índole académico, la mission civilisatrice era un slogan político que justificaba la dominación de una serie de territorios cuyos recursos podrían explotar económicamente y utilizar su posición como bases geoestratégicas que sirviesen a los intereses de las potencias coloniales.

Edward Said no fue el primer académico que expuso y denunció los métodos para el estudio, la comprensión y la representación occidental de Oriente ${ }^{31}$ como herramientas del imperialismo. Sin embargo, sería tras la publicación de Orientalismo cuando este término, junto con "orientalista" -tanto en la designación del conjunto de las materias que estudiaban tan vasto territorio como a los académicos y expertos que las trabajaban y el enfoque eurocéntrico aplicado- adquiriese una connotación negativa y se comenzasen a nombrar disciplinas encargadas de áreas geográficas más concretas $^{32}$. A pesar de la función que los estudios orientalistas tuvieron en el discurso político colonial e imperialista, como señala Zachary Lockman ${ }^{33}$ esto no significa que la gran mayoría de los académicos fuesen figuras conscientes de servir o justificar un fin imperialista ni invalida completamente aquellos trabajos realizados dentro de este marco, dado que muchos de ellos fueron esenciales como base para investigaciones posteriores, como los realizados por André Basset, H.A.R. Gibb, Henry Corbin o Bernard Lewis.

\footnotetext{
${ }^{28}$ SAID, Edward. Orientalismo. Debate, Barcelona, 2013 ( ${ }^{\circ}$ ed. publicada en I978), pp. 31 - 34.

29 WALLERSTEIN, Immanuel. El futuro de la civilización capitalista. Icaria, Barcelona, I999, p. 19 - 31.

${ }^{30}$ SAID, Edward. Orientalismo... op. cit. pp. 3I - 34.

31 Ver ABDEL MALEK, Anwar. "Orientalism in crisis", en Diogenes, n44, 1963.

${ }^{32}$ Como señala Gyan Prakash en su artículo "Orientalism Now" (History and Theory, vol. 34, n³, 1995, pp. 199-212) lo que provocó que Orientalismo tuviese un impacto mucho mayor a los estudios y discursos orientalistas fue que este insistió en la falsedad de las categorías inventadas e impuestas por las potencias occidentales, empezado por Oriente-Occidente, especialmente desde la disciplina académica.

${ }^{33}$ LOCKMAN, Zachary. Contending Visions of the Middle East:The History and Politics of Orientalism. Cambridge University Press, Nueva York, 2004 Pp. 73-75.
} 
En 1949, William A. Irwin ${ }^{34}$, especializado en lenguas y literatura del Antiguo Testamento, redactó un artículo acerca de la tarea que un orientalista debe llevar a cabo como historiador, tanto en la reconstrucción de unos hechos como en su interpretación. Irwin insiste en la existencia innegable de una única raza humana y, por tanto, de cómo solo es posible entender la historia desde una perspectiva y enfoque monista, el error que sería negar cómo la vida moderna es mejor que aquella vivida en periodos anteriores y del progreso como una constante histórica de mejora general de la vida e implícito en el carácter humano. La lectura completa del artículo muestra, sin lugar a dudas, el interés de Irwin en una naturaleza única humana y las características intrínsecas a esta naturaleza. Sin embargo, el autor se refiere en todo momento a la perspectiva y prácticas que los orientalistas deben mantener y realizar, siendo los estudios orientalistas una disciplina académica liderada por Europa y siendo todos los autores citados o europeos o norteamericanos.

Este texto encarna perfectamente la idea de los orientalistas como sujetos capacitados para descubrir, reconstruir e interpretar una serie de hechos históricos y diferentes culturas con el objetivo de representar la realidad de las sociedades orientales a las que se refiriesen. Esto es, precisamente, lo que llevaría a que los estudios orientalistas centrados en el mundo árabe e islámico de Oriente Medio dotasen de un significado propio a las fuentes históricas a las que fueron teniendo acceso, y explicasen las causas y efectos de todos los ámbitos sociales y culturales de las sociedades que habían residido y residían en estos territorios, incluyendo el islam, sus lenguas (con énfasis en el árabe, turco y persa), la arquitectura y organización de sus ciudades, el arte, la literatura o las prácticas sociales cotidianas.

En este sentido, es destacable la importancia que los orientalistas atribuyeron al mundo árabe y musulmán de Oriente Medio frente a las sociedades africanas musulmanas, o incluso de las árabes del Sahel. La representación e imagen proyectada del norte de África y Oriente Medio en Occidente varió considerablemente a lo largo del siglo XX. En base a los temas principales sobre los que los orientalistas centrarían su atención podríamos identificar tres grandes periodos historiográficos, y dentro de cada uno de ellos líneas de estudio, enfoques o teorías históricas y culturales a los que a su vez se concedería mayor crédito político, dado que operaban justificando los intereses geopolíticos y económicos de las potencias hegemónicas en cada periodo. De esta forma, podemos diferenciar, aproximadamente, un primer periodo que abarcaría desde 1900 a 1940, un segundo periodo que se prolongaría desde 1940 a 1980 y un tercero que constituirían las dos últimas décadas del siglo XX y el inicio del siglo XXI.

\section{I. Los antecedentes del MENA: civilizaciones, bloques culturales y su papel en el discurso político Occidental.}

En el primer periodo, entre 1900 y 1940, las escuelas orientalistas hegemónicas eran las europeas. Los académicos de este ámbito se centraron especialmente en la disección el islam como religión, en la lengua árabe (dada su extensión territorial y relevancia religiosa) y en la historia medieval de Oriente Medio, por lo que los temas más recurrentes eran la"civilización del islam", la expansión y apogeo del califato árabe y los imperios surgidos con su progresiva desintegración. Esta tendencia comenzará a diversificarse a partir del triunfo en 1923 del Movimiento Nacionalista Turco frente a los Aliados y del nombramiento como Shah de Irán al General Reza en 1925. Tanto Mustafá Kemal Atatürk como Reza Shah trataron de acelerar el proceso de modernización de sus respectivos

\footnotetext{
${ }^{34}$ IRWIN,William.A. “The Orientalist as Historian”, en Journal of Near Eastern Studies, vol. 8, n4, octubre de I949, pp. 298 - 309.
} 
países iniciando grandes reformas importadas del modelo occidental ${ }^{35}$, cuya puesta en marcha llevó a que aumentase la atención sobre Turquía e Irán.

Durante las décadas de 1940 y 1960, Occidente observó el auge de los movimientos nacionalistas, anticoloniales y antimperialistas, el nacimiento del tercer mundo como un pilar que se escapase de la bipolaridad que definía el orden mundial de la Guerra Fría, la renovada producción teórica y académica desde los territorios colonizados y la clara animosidad de todos los países árabes frente a la creación del Estado de Israel en territorio palestino. El panarabismo tuvo un papel central en la práctica totalidad de los estados árabes durante su proceso de independencia y su constitución como estados soberanos, a excepción de los países del Golfo Pérsico, y en especial, Arabia Saudí y Yemen del Norte ${ }^{36}$. Durante este mismo periodo, en Turquía se consolidaba una república secular y multipartidista inclinada hacia el bloque capitalista, y en Irán, Mohammed Reza Shah gobernaría el país en una férrea dictadura a través de la cual impondría reformas modernizadoras siguiendo el modelo occidental y reprimiendo toda oposición.

Así, el segundo periodo donde se observa un cambio temático y analítico en la historiografía occidental respecto a Oriente Medio y el norte de África se inicia en la década de 1940, con el despegue de los movimientos nacionalistas y antimperialistas, que trataban de compaginar la Modernidad con las que identificaban como culturas propias y el papel que el islam debía desempeñar en ello. Dicho periodo, durante el cual ganaría una gran importancia la escuela orientalista estadounidense, se prolongaría hasta el resurgimiento de los movimientos islámicos a partir de la década de 1980, en lo que se consideró como la prueba definitiva del "fracaso del socialismo árabe" tras la guerra de los Seis Días en 196737. Entre 1940 y la revolución de los Oficiales Libres de Egipto en 1952, continuará habiendo una parte importante de la historiografía centrada en el islam, las traducciones y en la historia medieval, pero el ascenso a la presidencia del General Gamal Abdel Nasser en 1954, su discurso de clara influencia socialista, su actitud beligerante contra Israel y la admiración que conseguiría por parte de otros países árabes tras la nacionalización del Canal de Suez en 1956, en lo que se vio como una fulminante victoria frente a las potencias coloniales europeas, fueron factores que sumaron nuevas temáticas a los ejes centrales en los análisis orientalistas.

En el ámbito de los estudios orientalistas se sumarían los trabajos respecto a la problemática generada por la división de Palestina y la creación del Estado de Israel en 1948, el movimiento de resistencia palestino a su ocupación y la posición beligerante de los países árabes frente a Israel; los movimientos revolucionarios en todo Oriente Medio y el norte de África; y por último, se inició todo un debate filosófico, histórico e ideológico sobre la compatibilidad o incompatibilidad del islam y la Modernidad y de la influencia de las ideas marxistas y socialistas en las sociedades árabe e iraní. Sin embargo, al contrario que en el periodo anterior, las perspectivas y enfoques desde los cuales se estudiarían estas temáticas no seguirían un mismo discurso, sino que se diversificarían.

${ }^{35}$ KEDDIE, Nikki. Modern Iran. Roots and Results of Revolution. Yale University Press, 2003, pp. 89 - I03; ATABAKI, Touraj. "The Caliphate, the Clerics and Republicanism in Turkey and Iran" en ATABAKI, Touraj y JAN ZURCHER, Erik (eds.) Men of Order:Authoritarian Modernisation in Turkey and Iran, 19/8-1942. IB. Tauris, Londres, 2004, pp. 45-6I.

36 VEIGA, Francisco; HAMAD ZAHONERO, Leyla; GUTIERREZ DE TERÁN, Ignacio. Yemen. La clave olvidada del mundo árabe 19 II - 20II. Alianza Editorial, 20I4, pp. 69-85; OCHENWALD,William. "Saudi Arabia and The Islamic Revival" en International Journal of Middle East Studies, vol. I3, n'. 3, agosto de 198I, pp. 27I-286.

37 ABU-RABI, Ibrahim. M. Contemporary Arab Though: Studies in Post-1967 Arab Intellectual History. Pluto Press, Londres, 2004, pp. 43-62. 
Mientras continuó siendo hegemónico el enfoque tradicional, desde el cual Occidente analiza y explica Oriente, en el ámbito académico comenzó a extenderse la desafección con respecto a la forma de estudio tradicional del norte de África y Oriente Medio, en especial entre los círculos académicos de marxistas y socialistas, que criticaban la falta de atención al factor económico, las relaciones de poder y la concepción del islam como unidad conceptual, como Maxime Rodinson ${ }^{38}$, Leonard Binder o la revista Review of Middle Eastern Studies, creada en $1975^{39}$.

Este nuevo contexto mundial tras la Segunda Guerra Mundial trajo consigo no solamente cambios en las tendencias y enfoques de las ciencias sociales y humanidades respecto a Oriente, sino en los discursos políticos y en la visión y división del mundo en áreas geoestratégicas que respondían a los intereses y prioridades políticas de las superpotencias. Los debates surgidos en Occidente por la descolonización y el surgimiento del tercer mundo, del enfrentamiento ideológico entre sistemas político-económicos y sociales opuestos y el intervencionismo en terceros países durante la Guerra Fría no se limitaba al ámbito político-económico, sino que este se justificaba constantemente en una serie de valores culturales que se identificaban y definían Occidente: modernidad, democracia, libertad individual, progreso, capitalismo. Por ende, el bloque comunista debía de representar no solo un sistema estructural e ideológico opuesto, sino culturalmente opuesto e históricamente justificable. Es decir, no solo se debía representar a Occidente, al bloque comunista $\circ$ al tercer mundo, sino que era necesario justificar científicamente las razones que daban lugar a estas imágenes.

Esto llevó a que, desde diferentes disciplinas tanto en EEUU como en Europa, especialmente desde la antropología, la historia, la sociología y los estudios culturales, se formularan y reformularan teorías históricas, culturales y políticas que mantuvieron el enfoque tradicional orientalista y servirían, voluntaria o involuntariamente, para justificar acciones que respaldaban los intereses geopolíticos del bloque capitalista, especialmente en la defensa y apoyo del Estado de Israel y a las empresas petrolíferas que operaban en Oriente Medio.Académicos de diferentes materias no solo participaron en la investigación de sus respectivos campos, sino que también formaban parte de grupos de análisis de relaciones internacionales o asuntos exteriores, como Arnold J.Toynbee, William H. McNeill, Fernand Braudel o Samuel P. Huntington, entre otros.

Dichas teorías, que pretendían dar una explicación general a las dinámicas mundiales, centrándose en la historia global y metodologías comparativas, utilizaron los estudios que durante más de un siglo habían realizado orientalistas tanto de la historia, sociedad, cultura u organización política de Oriente, representando así no solo Oriente, sino su papel con respecto al resto del planeta. Aunque autores como Max Weber y Oswald Spengler ya habían formulado teorías respecto al concepto de "civilización" y las grandes religiones a nivel mundial, posiblemente fue la teoría de las civilizaciones desarrollada por Arnold J. Toynbee la que más influencia tendría a este respecto durante el siglo XX. Entre 1934 y 196I, Toynbee publicaría su famosa obra de

38 Ver RODINSON, Maxime. Islam and Capitalism, Saqi Essentials, 1974 (Iºd. publicada en I966).

39 CHOUEIRI, Youssef. Modern Arab Historiography. Routeledge, Londres, 2003, pp. I-3. A este respecto, es muy ilustrativo ver la respuesta que dieron Roger Owen y Talal Asad al artículo escrito en 1979 por Clement Dodd, “The critique of Orientalism: a review”, criticando duramente el análisis realizado en un artículo publicado por Owen y Asad en Review of Middle Eastern Studies respecto a la metodología y enfoque tradicional de los estudios orientalistas de Oriente Medio. DODD, Clement. "The critique of Orientalism: a review" en Bulletin (British Society for Middle Eastern Studies), vol. 6, n², 1979, pp. 85-95; OWEN, Roger y ASAD, Talal, "The critique of Orientalism: a reply to Professor Dodd” en Bulletin (British Society for Middle Eastern Studies), vol.7, nI, I980, pp.33-38. 
I 2 volúmenes Estudio de la Historia, donde analiza de forma comparada las 21 civilizaciones identificadas por el autor a lo largo de la historia. Toynbee concibe la historia como una historia global, señalando que "la unidad inteligible del estudio histórico no es ni un estado nacional ni la humanidad como un todo, sino cierta comunidad humana que hemos llamado Sociedad"40. Esta "Sociedad" es lo que el autor denomina "civilización", las cuales siguen un desarrollo cíclico de cuatro fases: génesis, crecimiento, colapso y desintegración. Entre estas civilizaciones, Toynbee identifica cinco que continúan existiendo en el mundo contemporáneo: la Civilización Cristiana Occidental, la Civilización Cristiana Ortodoxa, la Civilización Islámica, la Civilización Hindú y la Civilización del Lejano Oriente ${ }^{4 !}$.

Toynbee concede un papel sumamente importante a la religión dentro de la configuración de las “civilizaciones", siendo su vertebrador cultural, especialmente a las dos grandes religiones monoteístas que definen tres de las cinco Sociedades vivas: el cristianismo y el islam. En la "civilización islámica", el autor incluye explícitamente a la civilización árabe y la iránica, e identifica esta última en la zona pérsico-turca. Considera que dichas Sociedades se tratan de "civilizaciones gemelas", filiales de la "civilización siríaca", de la que proviene el judaísmo y "en la cual el Profeta Muhammad encontró su inspiración" 42 . Toynbee se inspiró en los estudios de historia medieval e islam para proporcionar una explicación de la existencia de la "civilización islámica" contemporánea, considerando el islam el vertebrador de una civilización en la cual incluye otra serie de civilizaciones. En dicha labor, Toynbee sostuvo afirmaciones que no se corresponden con los trabajos desarrollados por los grandes orientalistas del siglo $X X$, como incluir a los turcos y a los persas en una misma civilización o tradición histórico-cultural.

Aunque el estudio de Toynbee fue duramente criticado desde diversos sectores por considerar que adolecía de lagunas históricas importantes, su obra sirvió como inspiración de obras posteriores que, utilizarían o reformularían las categorías de "civilización occidental" y "civilización islámica”, como es el caso de William H. McNeill, William R. Polk o S.N Eisenstadt. Al mismo tiempo, generarían un intenso debate en torno a la capacidad de las sociedades nooccidentales de insertarse en la Modernidad y de adaptarse a sistemas democráticos. Aunque intelectuales provenientes Oriente Medio y el norte de África, como Abdallah Laroui, Mohammed Abed al-Jabri, Anwar Abdel-Malek o Samir Amin, entre otros, participaron activamente en este debate y realizaron importantes aportaciones a esta cuestión durante las décadas de 1960 y 1970, en Occidente los análisis se centrarían en la falta de estados musulmanes modernos y democráticos, destacando la presencia del islam en la estructura de los nuevos estados-nación del norte de África y Oriente Medio y las dificultades para la modernización que esto suponía incluso en los estados con modelos socialistas como Egipto y Siria.

La imposibilidad de restringir la "civilización islámica" a Oriente Medio y el norte de África llevaría a que se señalase, al menos, el norte de Mali, Chad, Níger y Etiopía, así como todos los países comprendidos entre Irán, China y la India. Sin embargo, es evidente que existen grandes diferencias culturales en un territorio tan sumamente vasto. La hegemonía de la dialéctica moderna, con la consolidada categoría de "Nosotros" y la otrerización y representación de todo aquello

40 TOYNBEE, Arnold, J, SOMERVELL, D.C. Estudio de la Historia. Compendio I-IV. Alianza Editorial, Madrid, I998, (I ${ }^{\circ}$ ed. publicada en I946), p. 34

41 Ibidem. p. 24

42 Ibid, pp. 4 I -46 . 
que permaneciese fuera de esa categoría, constituía la base sobre la que se asentaría la influencia los estudios orientalistas en académicos y expertos centrados en elaborar teorías que explicasen, desde Occidente, el orden mundial. Estos darían una gran importancia al elemento árabe que está presente en el islam y situarían como su epicentro el mundo árabe y Oriente Medio. En este sentido, el orientalismo no solo influyó en el enfoque y concepción que se tenía de las sociedades del norte de África y Oriente Medio, sino también en la representación y justificación de su papel global histórica y contemporáneamente desde la perspectiva occidental, con énfasis durante, y a partir, de la Guerra Fría.

\subsection{La naturalización de las narrativas histórico-culturales tradicionales y su uso geo- estratégico: la popularización del MENA como categoría analítica.}

El último periodo en el que se produce un cambio historiográfico y discursivo en torno al mundo árabe e islámico de Oriente Medio es a partir de 1980. El debate iniciado con la publicación de Orientalismo, el resurgimiento de los movimientos y partidos políticos islamistas y la Revolución Islámica de 1979, cuyo discurso antimperialista, y en especial antiestadounidense y contra Israel, generó tanto un gran interés académico como alerta en EEUU. En la historiografía, dejaría de predominar el estudio de la historia medieval de Oriente Medio y el norte de África frente a la cuestión palestina y las guerras arabo-israelíes, el socialismo árabe, el auge de los movimientos islamistas, se intensificaría el debate de la posibilidad de construir un estado moderno musulmán o simplemente la posibilidad de otras culturas de ser estados-nación modernos exitosamente, o la génesis y consecuencias de la Revolución Islámica en Irán. De hecho, a partir de este momento es posible ver el considerable aumento de los análisis y estudios realizados desde el ámbito de las ciencias políticas y relaciones internacionales no solo en torno a Irán, si no su posible impacto en el área y los movimientos islamistas que pudiesen afectar a los intereses geopolíticos estadounidenses.

En la década de 1990 se popularizaría la utilización del término MENA en las ciencias políticas, relaciones internacionales y estudios de área para designar tanto a países árabes situados en el norte de África como al conjunto de países de Oriente Medio. Desde hacía varias décadas, esta región era considerada la parte esencial de la "civilización islámica" por su importancia histórica y cultural, entendiendo así que estos países comparten una historia, una estructura social, una cultura vertebrada en torno al islam, y al mismo tiempo mantienen una posición geoestratégica sumamente relevante, en especial en el comercio petrolífero y de mercancías entre el mar Mediterráneo y el océano Índico a través del mar Rojo.

Turquía, un país cuya historia lo relaciona tanto con los Balcanes como con los países del Mediterráneo, es sin embargo mayoritariamente musulmán y su situación geográfica funciona como frontera entre los países de mayoría musulmana de Oriente Medio de la Europa cristiana. Por otro lado, la representación del mundo árabe lo ha expuesto como el epicentro de la "civilización islámica" debido al origen de esta religión y a los elementos árabes presentes en ella, exportados con la expansión del califato árabe. Simultáneamente, los países del Golfo pérsico, que incluyen la península arábiga e Irán, es donde se sitúan las mayores reservas petrolíferas del mundo. Los países del cuerno de África, que se incluyen en el mundo árabe dependiendo de la temática de estudio, cuentan con la costa oeste del estrecho Bab al-Mandab, por el cual se accede al mar Rojo y se llega al canal de Suez o al golfo de Aqdaba, donde Israel, aliado histórico y geopolítico de 
Occidente en la región, tiene una salida al mar.

Desde una perspectiva histórica y cultural, la producción intelectual y académica occidental consideraba bien fundamentada la designación de todos los países del norte de África y Oriente Medio como una misma región, ya que sus sociedades compartían muchas más similitudes que diferencias. Esta será precisamente la idea que sería criticada en Orientalismo con vehemencia. De hecho, los dos mayores debates durante las décadas de 1980 y 1990 girarán en torno a dos obras esenciales publicadas en este periodo: la tesis de Orientalismo y la tesis de El choque de civilizaciones y la reconfiguración del orden mundial, publicada en 1996 por Samuel P. Huntington. Ambos libros tuvieron un enorme impacto, si bien el primero lo tuvo desde su publicación en 1978, especialmente en el ámbito académico, llegando a transformar cómo se entendían los estudios sobre el norte de África y Oriente Medio. Por otro lado, aunque la tesis inicial de Huntington sembró una importante polémica tras la publicación de su artículo "The Clash of Civilizations?" en la revista de Foreing Affairs en 1993, este no fue tan influyente en el momento de su publicación ${ }^{43}$.

En primer lugar, en el caso de Orientalismo el debate se centró entre aquellos que lo consideraron una contribución importante, entre quienes hubo críticos muy duros a la metodología de Said, y aquellos que consideraban directamente errónea toda su tesis, tanto en lo respectivo a la crítica de la narrativa tradicional orientalista en la Academia como en su argumentación de cómo este estaba impregnado en el discurso político y la influencia de las circunstancias políticas en la producción académica ${ }^{44}$. El debate en torno a la validez de la obra de Said se mantuvo vigente durante las siguientes dos décadas, en las cuales también se realizaron contribuciones en el estudio del norte de África y Oriente Medio sumamente relevantes que ponían de manifiesto la complejidad de la ya popularizada región del MENA, siendo algunos de los autores más destacables Hourani, Rodinson, Choueiri Nikki Keddie, Samir Amin,Abdallah Laroui, Mohammed Abed Al-Jabiri, Edmund Burke III o André Raymond entre otros ${ }^{45}$. De hecho, algunos de ellos, como Hourani y Rodinson, criticarían ciertos aspectos de Orientalismo por considerar que negaba en bloque la validez de muchos estudios realizados dentro de este ámbito, aunque reconocían la importancia de la obra de Said en tanto que ponía de manifiesto la tendencia de las escuelas orientalistas a la representación unilateral de las sociedades árabes e islámicas de Oriente Medio ${ }^{46}$.

Entre los autores que rechazarían completamente la tesis de Said destacaría uno de los historiadores de Oriente Medio e islam más reconocidos del siglo XX, Bernard Lewis, cuya opinión Orientalismo y las ideas recogidas en la obra quedaría plasmada en un artículo publicado por The

\footnotetext{
${ }^{43}$ ABRAHAMIAN, Ervand. "The US media, Huntington and September II” en Third World Quaterly, vol.24, n³, 2003, pp. 529 - 544. Recuperado de: https://sites.hks.harvard.edu/fs/pnorris/Acrobat/Abrahamian_Clash.pdf [21/03/2019]

44 PRAKASH, Gyan. “Orientalism Now”, op. cit. pp. 199 - 202

45 Los autores mencionados han realizado múltiples aportaciones tanto mediante artículos académicos como en obras en colaboración e individuales a lo largo de su carrera académica, algunas de las cuales ya se han utilizado como referencia en el presente artículo. De entre las obras que aún no han sido mencionadas, pueden destacarse HOURANI,Albert. The emergence of Modern Middle East, University of California Press, 198I; KEDDIE, Nikki: Women in the Middle East: past and present, Princeton University Press, 2007; RODINSON, Maxime. Europe and the mystique of Islam, I.B. Tauris, Londres, I988;AMIN, Samir: L'eurocentrisme: Critique d'une ideologie, Anthropos, París, I 988 (primera edición); ABDALLAH, Laroui: Islam et modernité, Editions La Découverte Paris, I986;ABDALLAH, Laroui. Islam et Historie, Albin Michel Éditions, I999; RAYMOND André. Grandes villes arabes à l'époque ottoman, Sindbad, París, I985;ABED AL-JABRI, Mohammed. Introduction à la critique de la raison arabe, Editions La Découverte, París, 1994.

46 RODINSON, Maxime. La fascination de I'Islam. François Maspero Paris, 1980, pp. I3 - I5; HOURANI, Albert, "The Road to Morocco", en The New York Revirew of Books, 8 de marzo de 1979. Recuperado de: https://www.nybooks.com/articles//979/03/08/the-road-to-morocco/ [consultado el 30/03/2019];
} 
New York Review of Books en 1982. Dicho artículo recogía una muy dura crítica a la obra e ideas planteadas por Said, que contaría con el apoyo de muchos otros académicos especializados en el norte de África y Oriente Medio, como Fred Halliday, Robert Irwin o Martin Kramer, entre otros. Dicha crítica, sin embargo, sería respondida por Edward Said y Oleg Garbarg un mes después mediante la publicación de un artículo en esa misma revista ${ }^{47}$.

Durante las siguientes dos décadas, el debate en torno a la validez de las narrativas clásicas en los estudios orientalistas del norte de África y Oriente Medio estuvo muy presente en la esfera académica y pública. Dicho debate presentaba las posturas de Edward Said y Bernard Lewis como antagónicas, lo que también trascendió al ámbito político debido al activismo del primero en la causa palestina, frente a la defensa de Lewis de Israel. Sin embargo, a partir del fin de la Guerra Fría y la caída del muro de Berlín en 1989 este debate se extendería ampliamente en la academia y en la esfera política cuando comiencen a surgir teorías en torno a un nuevo y posible enemigo eminente: el fundamentalismo islámico en el norte de África y Oriente Medio ${ }^{48}$.

En 1990, Bernard Lewis publicó un artículo titulado "The Roots of Muslim Rage"49, en el cual expuso la idea de un choque de civilizaciones entre la cultura judeo-cristiana y la islámica que, sin embargo, no es inevitable. En su artículo, Lewis expone que las sociedades islámicas del norte de África y Oriente Medio están reaccionando contra la histórica dominación e influencia Occidental, pero siendo su manifestación irracional al adscribirse a movimientos fundamentalistas islámicos, aunque no todas las ideas exportadas desde Occidente han sido rechazadas, sino que más bien se han mantenido, reformulado o fraguado mediante el contacto cultural, poniendo como ejemplo la redacción de constituciones o incluso ciertos hábitos de consumo ${ }^{50}$. Este artículo sería rescatado por Huntington en su artículo "The Clash of Civilizations?", publicado en 1993, que utilizaría a Lewis como principal referencia en el ámbito histórico-cultural para justificar las predicciones realizadas en su exposición ${ }^{51}$.

El artículo de Huntington en Foreing Affairs generó una enorme polémica desde su publicación, siendo la tesis central del mismo que, por un lado, los estados-nación continuarían siendo los actores fundamentales de las relaciones internacionales, al tiempo que exponía cómo en la post-Guerra Fría los mayores conflictos internacionales se producirían no por motivos políticos ni económicos, sino por las diferencias culturales entre civilizaciones, rescatando la teoría de las civilizaciones de Toynbee. Este mismo año, en febrero de 1993, Bernard Lewis publicaría un artículo en The Atlantic titulado "Islam and Liberal Democracy" ${ }^{52}$, que a pesar de tener mucha

\footnotetext{
47 LEWIS, Bernard, "The question of Orientalism" en The New York Review of Books, 24 de junio de 1982. Recuperado de: https://www. nybooks.com/articles/1982/06/24/the-question-of-orientalism/ [consultado el 30/03/2019]; SAID, Edward y GARBAR, Oleg, "Orientalism:An Echange" en The New York Review of Books, I 2 de Agosto de 1982. Recuperado de: https://www.nybooks.com/articles/I 982/08/I 2/orientalisman-exchange/ [consultado el 30/03/2019]

48 MONSHIPOURI, Mahmood y PETONITO, Gina, "Constructing the Enemy in the Post-Cold War Era:The Flaws of the "Islamic Conspiracy" Theory" en Journal of Church and State, vol.37, n4, 1995, pp.773-792.

49 LEWIS, Bernard. "The Roots of Muslim Rage” en The Atlantic, septiembre de 1990. Recuperado de: https://www.theatlantic.com/magazine/ archive/1990/09/the-roots-of-muslim-rage/304643/ [consultado el 30/03/2019]

50 Ibidem.

51 HUNTINGTON, Samuel. P.“The Clash of Civilizations?” en Foreing Affairs, vol.72, n³, I 993. Recuperado de: http://www.guillaumenicaise.com/ wp-content/uploads/2013/10/huntington_clash-of-civlizations.pdf [consultado el 23/03/2019]

52 LEWIS, Bernard. "Islam and the Liberal Democracy" en The Atlantic, 1993. Recuperado de: https://www.theatlantic.com/magazine/ archive/I993/02/islam-and-liberal-democracy/308509/ [consultado el I0/04/2019]
} 
menos repercusión que "The Roots of Muslim Rage”, posiblemente es más representativo que este último.

En este artículo, Lewis aborda fundamentalmente la cuestión de si la propia naturaleza del islam es compatible con la democracia liberal. En el análisis que lleva a la respuesta a esta pregunta, identifica como fundamentalismos islámicos a los movimientos islamistas en general, que habían comenzado a resurgir en la década de 1980, definiéndolos como históricamente intolerantes, fanáticos, agresivos y violentos y, por tanto, contrarios en sí mismos con la democracia liberal. Siendo la democracia liberal un producto heredado de la religión y ética judeo-cristiana y el derecho greco-romano, dando lugar a la "civilización moderna", sin que ningún sistema homólogo haya sido forjado en ninguna otra cultura, Lewis se pregunta si es posible adaptar este sistema a otras culturas, y de ser posible, si este podría sobrevivir. Lewis no termina de responder a la pregunta que plantea al inicio del artículo, concluyendo que la decisión de constituir países democráticos y libres es, por primera vez en siglos, "suya" 53 . Este "suyo", muy a pesar de referirse al islam y a su compatibilidad con la democracia liberal, hace referencia a los estados árabes, y puntualmente a la República Islámica de Irán, pero no implica al resto de países mayoritariamente musulmanes.

Este artículo es especialmente representativo ya que, siendo Bernard Lewis reconocido como una de las máximas autoridades en el estudio de Oriente Medio e islam del siglo XX, sus conclusiones acerca estas materias se consideraban avaladas por su trayectoria académica, lo que también ocurriría con sus publicaciones tras el $9 / 1 \mathrm{I}$ a pesar del enorme reduccionismo que realiza con respecto al fundamentalismo islámico ${ }^{54}$. Su concepción de la democracia como herencia histórica judeo-cristiana, sentando las bases de la "civilización moderna" y geográficamente limitada a Occidente, constituía el equivalente de la "civilización occidental" en los ensayos de Samuel Huntington, quien, tras el gran debate surgido de su artículo, publicaría el libro EI choque de Civilizaciones y la reconfiguración del orden mundial en 1996. En esta obra, Huntington reafirma la tesis sobre cómo los mayores conflictos futuros serán provocados por las diferencias culturales y no por cuestiones políticas o económicas, pero además esencializa la cultura de tal forma que esta no se considera fruto de un contexto histórico, político, económico o social determinado, sino que es algo inherente a los diferentes grupos humanos que conforman las grandes "civilizaciones", y rechaza la multiculturalidad como valor ideológico por ser imposible desprenderse del núcleo cultural a la que cada individuo pertenece ${ }^{55}$. Siguiendo toda esta lógica culturalista y determinista, Huntington rescata de nuevo el concepto de "civilización islámica", a la que divide en "subcivilizaciones", entre ellas la árabe, la persa, la turca y la malaya ${ }^{56}$, sin identificar aquellas de África que, al ser musulmanas, no incluye en la que tampoco termina por definir como "civilización africana"57.

La insistencia de Huntington en representar como una realidad natural la existencia de una

\footnotetext{
53 Ibidem.

${ }^{54}$ Ver LEWIS. Bernard. What went wrong? Western Impact and Middle Eastern Response. Oxford University Press, 2002; LEWIS, Bernard, The Crisis of Islam: Holy War and Unholy Terror. The modern library, Nueva York, 2003.

${ }^{55}$ HUNTINGTON, Samuel. El choque de Civilizaciones y la reconfiguración del orden mundial. Paidós, 2015 ( ${ }^{\circ}$ ed. publicada en I996), p. 337

56 Ibidem, p. 38 - 39.

57 Ibid, p. 40.
} 
“civilización islámica”, representando como un solo bloque cultural todas las sociedades que se incluyen en ella, constituye posiblemente la muestra más clara de la persistencia de las categorías "Nosotros" y un "otro" al que Occidente define y sitúa en el mundo más de veinte años después de que se iniciase públicamente el debate y la crítica de lo que Said denominó "orientalismo". Aunque según Abrahamian, el éxito de la teoría del "choque de civilizaciones" tuvo mucho más que ver con el uso mediático que se hizo de esta tras el los atentados del II de septiembre, considerándose incluso "premonitoria" 58 , el discurso político hegemónico en Occidente no ha terminado de desechar categorías que han generado históricamente opresiones en el norte de África y Oriente Medio. Como es posible observar a través de determinados análisis políticos, sociales y culturales actuales, estas categorías simplemente se han reformulado, manteniendo la base discursiva sobre la cual fue construida. La naturalización de la categoría analítica de MENA y su empleo como forma de generalizar respecto a los actores que designa, a pesar de la diversidad interna de estos, su elasticidad y la vaguedad de este concepto en su significación, es un ejemplo de ello.

\section{Conclusiones}

A pesar de que el debate en torno a la categoría analítica del MENA aparece en la década de I 970 con el desarrollo de teorías posestructuralistas como la teoría decolonial, postcolonial o el constructivismo en las Relaciones Internacionales, este debate no ha destacado por su intensidad en los ámbitos de las Relaciones Internacionales, la Historia o su trascendencia al ámbito político. Así, MENA pretende hacer referencia a una zona geográfica cuyos países comparten un pasado histórico y los suficientes rasgos culturales como para ser considerados parte de una misma entidad, reconociendo simultáneamente su pluralidad cultural interna. Esto lleva a plantearse bajo qué criterios se incluyen o excluyen una serie de países si teóricamente estos se agrupan en base a unos rasgos culturales comunes y la conformación de un área geográfica determinada.

La escuela orientalista europea ha tendido, desde el siglo XIX a transcurrida la Segunda Guerra Mundial, a centrar sus estudios en la disección del islam y la historia medieval de Oriente Medio, atribuyendo un papel protagonista en la historia de la región a la expansión del califato árabe, y con él del islam, que también se extendió por África a través de rutas comerciales. El énfasis puesto en el vínculo entre la cultura árabe y el islam, sin embargo, llevó a identificar ambas cuestiones a pesar de que tanto en Turquía, Irán y las diferentes sociedades del Sahel y el cuerno de África tuvieron lugar experiencias históricas diversas que llevaron a la diferente adaptación y asimilación del islam en sus respectivas sociedades. Si bien se mantienen presentes los elementos árabes de los que no puede desprenderse la fe islámica, el islam ha sido, en diferente medida y mediante diferentes procesos, adaptado a las idiosincrasias culturales locales, algo en lo que los estudios orientalistas han incidido mucho menos que en la experiencia islámica en Oriente Medio y el mundo árabe.

Durante el orden mundial bipolar de la Guerra Fría, muchos académicos desarrollaron teorías que pretendían explicar las dinámicas mundiales y el grado de progreso alcanzado por unas y otras sociedades a través de la historia y los estudios culturales, desembocando en la reducción del mundo a teorías civilizatorias, culturalistas y deterministas que continuaban manteniendo un enfoque clásico orientalista, lo cual se denunció y puso de relieve por diversos autores desde

\footnotetext{
58 ABRAHAMIAN, Ervand. “The US media, Huntington and September II ...”, op. cit. 53I - 538.
} 
la década de 1960, y que ganará una especial visibilidad tras la publicación de Orientalismo. Sin embargo, a pesar del debate sembrado en el ámbito académico por la tesis de Said y otras obras de referencia en cuanto a construcción identitaria y lenguaje, las teorías civilizatorias surgidas durante la Guerra Fría trascendieron considerablemente al ámbito político. Desde el mismo fin del orden bipolar la "civilización islámica", al igual que la "civilización moderna" o la "civilización occidental", se naturalizó como parte de una realidad objetiva, alcanzando su culmen con El choque de Civilizaciones, de Samuel Huntington. La relación entre "lo árabe" y lo islámico, la apelación a un pasado común y el movimiento panarabista fueron factores clave para homogeneizar estos territorios y considerarlos una misma región. Con un enorme valor geoestratégico para Occidente, el MENA se consolidaría como categoría analítica cuyo empleo puede observarse en diversas especializaciones a nivel global.

Si bien su construcción ha sido un proceso de hibridación y no meramente unilateral, la elasticidad en el extendido empleo de la categoría analítica de MENA su y acepción cuentan con un importante componente de designación occidental. A través de la producción intelectual y académica orientalista, puede observarse un proceso de homogeneización cultural que ha planteado diversas dificultades, entre ellas conceptuales en cuanto a la definición de realidades sociales muy plurales. Esta cuestión, si bien ya se ha señalado que ha contado con estudios muy relevantes, carece de líneas de investigación extensas tanto en el ámbito de las Relaciones Internacionales como de la Historia. Sin embargo, el repensar el uso de la categoría del MENA desde diferentes perspectivas supone un ejercicio de investigación necesario para que esto trascienda a disciplinas donde su utilización sigue sumamente presente a día de hoy.

\section{Bibliografía}

ABD AL-RAHIM, Muddathir." Arabism,Africanism, and Self-Identification in the Sudan" en The Journal of Modern African Studies, vol. 8, $n^{\circ}$. 2, (pp.233-249)-

ABRAHAMIAN, Ervand. “The US media, Huntington and September II" en Third World Quaterly, vol.24, n³, 2003, pp. 529 - 544. Recuperado de: https://sites.hks.harvard.edu/fs/pnorris/Acrobat/Abrahamian_Clash.pdf [consultado el 2I/03/2019]

ABU-RABI, Ibrahim. M. Contemporary Arab Though: Studies in Post-1967 Arab Intellectual History. Pluto Press, Londres, 2004.

AGUDA, Oluwadare, "Arabism and Pan-Arabism in Sudanese Politics", en The Journal of Modern African Studies, vol. I I, $\mathrm{n}^{\circ} 2$, junio de 1973 (pp. 177-200).

ATABAKI, Touraj. "The Caliphate, the Clerics and Republicanism in Turkey and Iran" en ATABAKI, Touraj y JAN ZURCHER, Erik (eds.) Men of Order: Authoritarian Modernisation in Turkey and Iran, 19/8-1942, IB.Tauris, Londres, 2004.

ATÇIL, Abdurrahman, "Decentralization, Imperialism, and Ottoman Sovereignty in the Arab Lands before 19/4: Shak $\square$ b ArsI $\square$ n's Polemic against the Decentralization Party", en Die Welt des Islams, vol. 53, nI, 2013 (pp. $26-49)$.

BALCI, Bayram. Islam in Central Asia and the Caucasus Since the Fall of the Soviet Union. Oxford University Press, Nueva York, 2018.

BILGIN, Pinar. "Whose 'Middle East?' Geopolitical Inventions and Practices of Security" en International Relations, vol. $18, n^{\circ}$ I, pp. $17-33$.

BONINE, E. Michael. "Where is the geography of the Middle East", en The Professional Geographer, vol. 28, n 2, 1976.

CHOUEIRI,Youssef. M. Arab Nationalism. A history. Blackwell Publishers, Oxford. 2000.

CHOUEIRI,Youssef. Modern Arab Historiography. Routeledge, Londres, 2003

DODD, Clement. “The critique of Orientalism: a review” en Bulletin (British Society for Middle Eastern Studies), vol. $6, n^{\circ} 2,1979$,

FIERRO, Maribel (Ed). The New Cambridge History of Islam, vol. II:The Western Islamic World Eleventh to Eighteenth Centuries. Cambridge University Press, Cambridge, 2010.

HAYKEL, Bernard. "Western Arabia and Yemen during the Ottoman period" en The New Cambridge History of Islam, vol. II:The Western Islamic World Eleventh to Eighteenth Centuries. Cambridge University Press, Cambridge, 20 I0. 
HOURANI, Albert. A History of Arab Peoples. Faber and Faber, 1991.

HUNTINGTON, Samuel. El choque de Civilizaciones y la reconfiguración del Orden Mundial. Paidós, 2015.

INSOLL, Timothy. The Archaeology of Islam in Sub-Saharian Africa. Cambridge University Press, Cambridge, 2003.

IRWIN,William. A. “The Orientalist as Historian”, en Journal of Near Eastern Studies, vol. 8, n4, octubre de 1949, (pp. $298-309)$.

KEDDIE, Kikki.“Is There a Middle East?” en International Journal of Middle East Studies, vol. 4, n 3, I 973, pp. 255-27I.

KEDDIE, Nikki. Modern Iran. Roots and Results of Revolution. Yale University Press, 2003.

KNUT.Vikor. "Sudan, Somalia and the Maghreb to the end of the First World War" en The Cambridge History of Islam, vol.V:The Islamic World in the Age of Western Dominance. Cambridge University Press, Cambridge, 2010.

KÜNG, Hans. El islam. Editorial Trotta, Madrid, 2006.

LAUZIËRE, Henri. "The Construction of Salafiyya: Reconsidering Salafism From The Perspective Of Conceptual History”, en International Journal of Middle East Studies, vol. 42, n 3, agosto del 2010 (pp. 369 - 389).

LOCKMAN, Zachary. Contending Visions of the Middle East:The History and Politics of Orientalism. Cambridge University Press, Nueva York, 2004.

MARTIN, B.G. "Arab Migrations to East Africa in Medieval Times”, en The International Journal of African Historical Studies, vol. 7, n. 3, 1974, (pp. 367-390).

MAZURI, Ali A. "Religion and Political Culture in Africa" en Journal of the American Academy of Religion, vol. 53, n 4. I 985 (pp. 817-839)

MONSHIPOURI, Mahmood y PETONITO, Gina, “Constructing the Enemy in the Post-Cold War Era:The Flaws of the "Islamic Conspiracy" Theory" en Journal of Church and State, vol.37, n4, 1995 (pp.773-792)

OCHENWALD, William. "Saudi Arabia and The Islamic Revival" en International Journal of Middle East Studies, vol. I 3 , $\mathrm{n}^{\circ}$. 3, agosto de I98I (pp. 27I-286).

OWEN, Roger y ASAD, Talal, “The critique of Orientalism: a reply to Professor Dodd” en Bulletin (British Society for Middle Eastern Studies), vol.7, n'I, 1980.

PRAKSH, Gyan. “Orientalism Now” en History and Theory, vol. 34, n³, 1995 (pp. 199-2I2).

REBSTOCK, Ulrich. "West Africa and its early empires", en FIERRO, Maribel (Ed). The New Cambridge History of Islam, vol. II:The Western Islamic World Eleventh to Eighteenth Centuries. Cambridge University Press, Cambridge, 2010.

ROBINSON, David. Muslim Societies in African History. Cambridge University Press, 2004.

RODINSON, Maxime. La fascination de l'Islam. François Maspero Paris, 1980

ROUGHI, Ramzi. "Why are there no Middle Easterners in the Maghrib" en BONINE, Michael. E, AMANAT, Abbas, GASPER, Michael Ezekiel (eds.) en Is There a Middle East? The evolution of a geopolitical concept, Stanford University Press, Stanford, 2012, pp. 100 - II6.

ROUIGHI, Ramzi. "The Berbers of the Arabs" en Studia Islamica, vol. I06, n I, 201 I.

SAID, Edward. Orientalismo. Debate, Barcelona, 2013.

SHARKEY, Heather J. "Arab Identity and Ideology in Sudan:The Politics of Language, Ethnicity, and Race”, en African Affairs, vol. 107, n426, 2008 (pp.2I-43)

TETI, Andrea y ABBOTT, Pamela. "What People Want? The Demand for Democracy in Six Middle Eastern States" en Report number:Arab Transformations Policy Brief I, Universidad de Aberdeen, enero de 2018.

TETI,Andrea."Bridging the Gap: IR, Middle East Studies and the Disciplinary Politics of the Area Studies Controversy" en European Journal of International Relations, vol. I3, n I, PP. II 7 - I45.

TOYNBEE, Arnold, J, SOMERVELL, D.C. Estudio de la Historia. Compendio I-IV.Alianza Editorial, Madrid, 1998.

VALBJØRN, Morten. "The Meeting of the Twain: Bridging the Gap between International Relations and Middle East Studies" en Cooperation and Conflict, vol 38, n², 2003 pp. 163 - I 73.

VEIGA, Francisco; HAMAD ZAHONERO, Leyla; GUTIERREZ DE TERÁN, Ignacio. Yemen. La clave olvidada del mundo árabe 19II - 20II.Alianza Editorial, 2014.

VIKOR, S. Knut. "Sufi Brotherhoods in Africa" en LEVTZION, Nehemia y POWELS, Randall. L. The History of Islam in Africa. Ohio University Press, Atenas, 2000.

WALLERSTEIN, Immanuel. El futuro de la civilización capitalista. Icaria, Barcelona, 1999.

WENDT,Alexander: Social Theory of International Politics, Cambridge University Press, 1999

- $\quad$ Artículos en prensa:

HOURANI, Albert, “The Road to Morocco”, en The New York Revirew of Books, 8 de marzo de 1979. Recuperado de: https://www.nybooks.com/articles/1979/03/08/the-road-to-morocco/ [consultado el 30/03/2019]

HUNTINGTON, Samuel. P. “The Clash of Civilizations?” en Foreing Affairs, vol.72, n³, 1993. Recuperado de: http:// www.guillaumenicaise.com/wp-content/uploads/20I3/I0/huntington_clash-of-civlizations.pdf [consultado el 23/03/2019]

LEWIS, Bernard, “The question of Orientalism” en The New York Review of Books, 24 de junio de 1982. Recuperado de: https://www.nybooks.com/articles/I982/06/24/the-question-of-orientalism/ [consultado el 30/03/20I9]

LEWIS, Bernard. "Islam and the Liberal Democracy" en The Atlantic, 1993. Recuperado de: https://www.theatlantic. $\mathrm{com} / \mathrm{magazine} /$ archive/ /993/02/islam-and-liberal-democracy/308509/ [consultado el 10/04/2019]

LEWIS, Bernard. "The Roots of Muslim Rage" en The Atlantic, septiembre de 1990. Recuperado de: https://www. theatlantic.com/magazine/archive/ I990/09/the-roots-of-muslim-rage/304643/ [consultado el 30/03/2019]

SAID, Edward y GARBAR, Oleg, "Orientalism:An Echange” en The New York Review of Books, I2 de Agosto de 1982. 
Recuperado de: https://www.nybooks.com/articles/1982/08//2/orientalism-an-exchange/ [consultado el $30 / 03 / 2019]$

\section{- Webs:}

Alto Comisionado Derechos Humanos de las Naciones Unidas https://www.ohchr.org/en/countries/menaregion/ Pages/MenaRegionIndex.aspx [consultado el I5/03/20I9]

Banco Mundial: https://www.worldbank.org/en/region/mena [consultado el 15/03/2019]

Estrategia de Política Exterior y de Seguridad de la Unión Europea (2016) http://eeas.europa.eu/archives/docs/top stories/pdf/eugs_review_web.pdf [consultado el I5/03/2019]

Informe Final (2019) del Proyecto MENARA, gestionado por el CIDOB https://www.cidob.org/es/publicaciones/ serie_de_publicacion/menara_papers/working_papers/the_mirage_of_regionalism_in_the_middle_east_ and_north_africa_post_20II [consultado el 15/03/2019] 


\section{RELACIONES INTERNACIONALES}

Revista académica cuatrimestral de publicación electrónica Grupo de Estudios de Relaciones Internacionales (GERI)

Universidad Autónoma de Madrid, España

https://revistas.uam.es/relacionesinternacionales

ISSN 1699 - 3950

f facebook.com/RelacionesInternacionales

3. twitter.com/RRInternacional

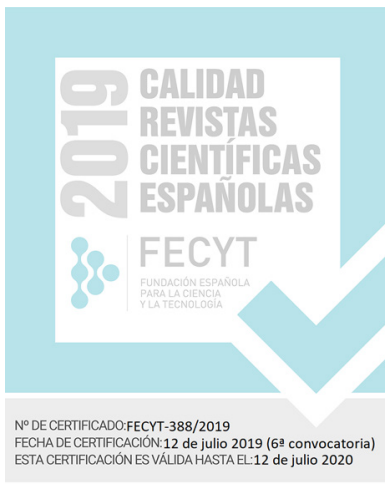

